\title{
Situação de rua: condição que vulnerabiliza ao consumo de substâncias psicoativas
}

\section{Street situation: condition that vulnerabilizes the consumption of psychoactive substances}

\author{
Ítalo Arão Pereira Ribeiro' • Abigail Laísla Belisário da Silva² • Luan Ribeiro dos Santos Assis ${ }^{3}$ \\ Marcos Ramon Ribeiro dos Santos Mendes ${ }^{4}$ Isadora Nunes Amaral $^{5}$
}

O desenvolvimento tecnológico e as relações originadas pelo capitalismo globalizado promoveram uma nova forma de organização da sociedade, trazendo profundas alterações nas relações sociais com o enfraquecimento dos laços que teciam as redes comunitárias. Uma das problemáticas mais sérias geradas pelo capitalismo é a exclusão, provocada por inúmeros e graves problemas sociais, a exemplo da extrema pobreza, ausência de educação adequada, falta de oportunidades, desemprego em massa, os quais geram fome, violência, desesperança e impotência diante da vida e no próprio convívio com as drogas ${ }^{(1)}$.

Nessas condições, parcelas significativas da população, a cada dia se vêm, inesperadamente, sem condições de colocação no mercado de trabalho e sem nenhuma possibilidade de assegurar as condições mínimas para uma vida digna, levando-os a buscar formas de vida que respondam a este crescente processo de exclusão(1).

De acordo com os autores ${ }^{(2)}$, a existência de população em situação de rua é um fenômeno social que assume expressões novas na sociedade contemporânea, particularmente nos grandes centros urbanos. Esse grupo social, que habita em logradouros ou em albergues públicos ou filantrópicos, vivencia situações de trabalho, condições de vida e inserções sociais precárias. Viver em situação de rua é um problema que ultrapassa a falta de moradia. Ter uma casa significa ter raízes, identidade, segurança, sentimento de pertencimento e um lugar de bem estar emocional.

Nesse contexto, a literatura demonstra uma importante interface entre o uso de substâncias e essa população. Em especial, a condição de morar na rua está associada a uma série de vulnerabilidades de saúde, sociais e legais, que exacerbam sua marginalização social, especialmente ao uso de Substâncias Psicoativas (SPAs) ${ }^{(3)}$.

Estudo, que avaliou as exposições de riscos quanto ao uso de álcool e outras substâncias, em indivíduos moradores de rua, obteve os seguintes dados: $57 \%$ são fumantes; $34 \%$ consumem álcool, dos quais $18 \%$ relataram o consumo de mais de três doses por vez e 19\% responderam afirmativamente a três ou quatro questões do Cut Down, Annoyde by Criticims, Guilty e Eye-Opener (CAGE) (consumo de risco). Cerca de um terço referiu já ter usado maconha; $10 \%$ a $14 \%$ referiram o uso de cocaína inalada, crack, anfetamina; $8 \%$ relataram o uso de lança perfume, cola, loló e outras drogas inaladas; $5 \%$ referiram o uso de drogas injetáveis, LSD ou ecstasy ${ }^{(2)}$.

O consumo de SPAs é um problema complexo, relacionado a fatores de tipos muito diferentes, como a tolerância social e a falta de observância de normas e leis, a disponibilidade de substâncias, crime e violência social, a deterioração das relações sociais e família, as deficiências sociais relacionadas à pobreza e outros fatores intrínsecos aos consumidores destas substâncias. Com isso, alguns estudos latino-americanos evidência, na população adolescentes, cujas famílias vivem na pobreza e na exclusão social, os tornam mais vulneráveis em relação ao consumo de álcool e outras SPAs ${ }^{(4)}$.

I Ítalo Arão Pereira Ribeiro - Enfermeiro, Doutorando em Enfermagem pelo Programa de Pós-Graduação em Enfermagem pela Universidade Federal do Piauí (PPGEnf/UFPI).Teresina, Piauí - Brasil. E-mail: italoaarao@hotmail.com;

2 Abigail Laísla Belisário da Silva - Enfermeira, graduada pela Faculdade Maurício de Nassau/Aliança.Teresina, Piauí - Brasil. E-mail: abigail.laaisla@gmail.com;

3 Luan Ribeiro dos Santos Assis - Enfermeiro, Mestrando em Atenção em Saúde pela Universidade Federal do Triângulo Mineiro (UFTM). Enfermeiro do Hospital das Clínicas da Universidade Federal do Triângulo Mineiro (HCUFTM). Uberaba, Minas Gerais - Brasil. E-mail: luanrsa@hotmail.com;

4 Marcos Ramon Ribeiro dos Santos Mendes - Enfermeiro, Mestre em Saúde Pública pela Universidad Internacional Tres Fronteras (UNINTER-ASUNCIÓN). Enfermeiro do Hospital Universitário da Universidade Federal do Vale do São Francisco (HUUNIVASF). Petrolina, Pernambuco - Brasil. E-mail: marcosramon@ hotmail.com;

5 Isadora Nunes Amaral - Enfermeira, Especialista em Enfermagem do Trabalho e Saúde Ocupacional pela Universidade Cândido Mendes (UCAM). Rio de Janeiro, Rio de Janeiro - Brasil. E-mail: isadora.n.amaral@hotmail.com 
O uso de drogas deve ser analisado a partir de três dimensões, sujeito-substância-contexto sociocultural, afirmando que somente a partir desta equação é possível compreender os efeitos da droga. Tanto no âmbito individual como social, se faz necessária uma perspectiva bio-psico-sócio-cultural relacionada ao uso destas substâncias, uma vez que seus efeitos não dependem somente de suas propriedades farmacológicas, mas, também, dos contextos nos quais se formam as necessidades individuais, das épocas históricas e das culturas em que são utilizadas ${ }^{(1)}$.

Inserido nesse cenário, o ambiente de rua pode propiciar/maximizar o uso de drogas psicoativas, inclusive porque tal consumo pode significar uma forma de pertencerem ao grupo da rua, possivelmente compondo estratégias de sobrevivência na medida em que os efeitos do uso dessas substâncias produzem sensações de prazer, euforia e poder contra a dolorosa realidade externa, que é viver na rua ${ }^{(5)}$.

Os autores ${ }^{(6)}$ apontam que estudos internacionais, americanos e ingleses, assimilam grande prevalência de alcoolismo na população rualizada, em comparação à população em geral, tornando-os mais vulneráveis a acidentes e a problemas físicos e/ou mentais, principalmente relacionados ao abuso e/ou dependência de álcool. Já no Brasil, entre os principais motivos para a rualização encontram-se os problemas de alcoolismo e/ou drogas, desemprego e desavenças familiares. Entre os fatores da rualização encontram-se os estruturais, biográficos e desastres de massa e/ou naturais.

O cotidiano da vida nas ruas é apontado como experiência marcada pela miséria, por relações de violência, vínculos com a criminalidade, preconceito, impotência, solidão e desespero. Os sujeitos narraram situações nas quais são roubados, estuprados, violentados, se envolvem em brigas e disputas por objetos ou território, sofrem preconceito generalizado e ações de violência por parte da sociedade, e estando em sua grande maioria envolvidos continuamente com o uso problemático de substâncias psicoativas ${ }^{(7)}$.

Dessa forma, vulneráveis a um conjunto complexo de fatores biopsicossociais, faz-se necessário que as políticas públicas e as ações sociais voltem seus olhos a esse segmento populacional, pois esses indivíduos devem ser compreendidos como parte integrante da sociedade em geral, e que tal como as outras parcelas dessa coletividade, possuem necessidades e direitos de serem amparados pelo poder público e englobados, de forma significativa, em suas ações de promoção e prevenção à saúde, dignidade humana e nos programas e estratégias de combate ao consumo de SPAs. 


\section{REFERÊNCIAS}

I. Tondin M, Barros-Neta M, Passos L. Consultório de Rua: intervenção ao uso de drogas com pessoas em situação de rua. Revista de Educação Pública. 20I3; 22 (49/2): 485-50 I. http://periodicoscientificos.ufmt.br/ojs/index.php/educacaopublica/article/view/929

2. Barata RB, Carneiro JN, Ribeiro MCSA, Silveira C. Desigualdade social em saúde na população em situação de rua na cidade de São Paulo. Saude soc. 2015; 24 (Suppl I): 219-232. http://www.scielo.br/scielo.php?script=sci_arttext\&pid=SO I 04- I 29020150005002 I $9 \&$ Ing=en. https://doi. org/I0.1590/s0104-129020I5s01019.

3. Halpern SC, Scherer JN, Roglio V, Faller S, Sordi A, Ornell $F$. et al. Vulnerabilidades clínicas e sociais em usuários de crack de acordo com a situação de moradia: um estudo multicêntrico de seis capitais brasileiras. Cad. Saúde Pública. 2017; 33 (6): e00037517. http:// www.scielo.br/scielo.php?script =sci_arttext\&pi$d=S 0102-3$ I I X20 I 7000605002\&Ing=en. Epub July 03, 2017. https://doi.org/I0.1590/0102-3IIx000375I7.

4. Abeldaño RA, Fernández AR, Ventura CA, Estario JC. Con- sumo de sustancias psicoactivas en dos regiones argentinas y su relación con indicadores de pobreza. Cad. Saúde Pública .20 I 3; 29 (5):899-908. http://www.scielo.br/scielo.php?script=sci_arttext\&pid=SO | 02 =3 | | -20 | 3000500007X\&lngen. https://doi.org//0.1590/S0 I02-3IIX2013000500007.

5. De Tilio R, Vidotto LT, Galego PS. Medos e expectativas de usuários de drogas em situação de rua. Rev. SPAGESP . 20I5; I6( 2 ): 75-87. http://pepsic.bvsalud.org/scielo.php?script=sci_arttext\&pid=SI 677-297020 I 5000200007\&lng=pt.

6. Botti NCLetal.Padrão de uso deálcool entre homens adultos em situação de rua de Belo Horizonte. SMAD, Rev. Eletrônica Saúde Mental Álcool Drog. (Ed. port.). 2010; 6 (spe): 5365559. http://pepsic.bvsalud.org/scielo.php?script=sci_arttext\&pid=S I 806-697620 I00003000 I 0\&lng=pt\&nrm=iso

7. Fiorati RC, Carretta RYD, Kebbe LM, Cardoso BL, Xavier JdaS.As rupturas sociais e o cotidiano de pessoas em situação de rua: estudo etnográfico. Rev. Gaúcha Enferm. 2016; 37(spe): e7286I. http://www.scielo.br/scielo.php?script=sci_arttext\&pid=S | 983- | 44720 |6000500427\&lng=en. https://doi.org/|0.1590/|983-|447.20 I6.esp.7286I. 